\title{
A methodological Critique of the Interpretive Ranking Process for Examining IS Project Failure
}

\author{
Laurie Hughes \\ Emerging Markets Research Centre (EMaRC) \\ School of Management \\ Swansea University Bay Campus, \\ Swansea, SA1 8EN, Wales, UK \\ Email: D.L.Hughes@swansea.ac.uk
}

Yogesh K. Dwivedi ${ }^{1}$

Emerging Markets Research Centre (EMaRC)

School of Management

Swansea University Bay Campus

Swansea, SA1 8EN, Wales, UK

Email:y.k.dwivedi@swansea.ac.uk

Phone: 00441792602340

Nripendra P. Rana

School of Management

University of Bradford, BD9 4JL, UK

Email: n.p.rana@bradford.ac.uk.

${ }^{1}$ Corresponding author 


\begin{abstract}
This research critically analyzes the Interpretive Ranking Process (IRP) using an illustrative empirically derived IS project failure related case study to articulate a deeper understanding of the method. The findings emphasize the suitability of the method for a number of practical applications, but also highlight the limitations for larger matrix sized problems. The IRP process to derive the dominance between IS project failure factors is judged to be methodical and systematic, enabling the development of clear dominating interactions.
\end{abstract}

Keywords - IS project failure, Interpretive Ranking Process, factor interrelationships, factor dominance

\title{
1. Introduction
}

The failure of IS projects has been a constant theme for over four decades with studies articulating a diverse range of contributory factors (Aladwani et al. 2016, Aranyossy et al., 2017, Cule et al. 2000, Dwivedi et al. 2015, Hughes et al. 2015, Kappelman et al. 2006, Malaurent \& Avison 2015, Martinsons et al. 2017; McComb \& Smith 1991, Murray 2001, Pan et al. 2008, Peterson et al. 2002, Park et al. 2017, Standish Group 2013). Studies that have analysed IS project performance highlight that only $28 \%$ of IS projects were judged to be successful. Success rates were reported as $29 \%$ in 2012, indicating that the industry as a whole has fundamentally failed to address this problem (Standish Group 2015). The National Audit Office (NAO) report on the failed $£ 125.9 \mathrm{~m}$ DMI project (BBC 2017a) and significantly delayed $£ 830 \mathrm{~m}$ e-borders scheme (BBC 2017b), highlight the huge waste of public funds expended on IS related projects and inability to learn the lessons of failure. The abandoned National Programme for IT $-\mathrm{a}$ $£ 10$ bn project to computerise the patient records of 220 NHS trusts throughout the UK, was described by the public accounts committee as "one of the most expensive failures in the history of the public sector..." (BBC 2017c). These examples highlight the huge waste of public funds and inability to learn the lessons from failure.

The diverse factor-based narrative on the root causes of government IS project failure has yielded many critical factors such as: poor project and change management, poor planning, inadequate project sponsorship and omission to learn lessons from previous projects (Beynon-Davies 1995, Mitev 1996). However, despite a wide body of literature that has sought to elucidate the key factors and root causes; IS project failure in the public and private sectors is still a recurring problem (Dwivedi et al. 2015). Government IS projects by their very nature are often large, complex and transformational in nature involving multiple stakeholders, often exhibiting unrealistic expectations and high levels of user resistance (Goldfinch 2007). Studies have articulated the challenges posed by large and complex IS projects, highlighting that they are extremely difficult to control, have a virtually zero chance of being delivered successfully and that failure at some level 
is inevitable (Goldfinch 2007, Hughes et al. 2015, Sitkin 1992, Standish Group 2013). These size related factors are relevant to both private and public sectors where scale and complexity can dramatically increase risk, unless countered by mitigating actions to reduce the threat to the project (Hughes et al. 2016).

Researchers have explored the deeper analysis of the underlying factors relating to IS project success and failure in the context of factor interrelationships and causal links (Belout and Gauvreau 2004, Delone and McLean 1992, 2003). Further studies have undertaken IS specific factor analysis utilising pairwise methods such as Interpretive Structural Modelling (ISM) and Interpretive Ranking Process (IRP) (Hughes et al. 2016; 2017). However, although ISM has received widespread adoption within the literature offering detailed explanations on the methodology, researchers have yet to offer any meaningful reflection on the use of IRP.

This research aims to fill this gap by providing greater clarity on the use of the IRP methodology via a case study analysis of an implementation of the method from Hughes et al. (2017) that analyzes the interrelationships between the factors surrounding IS failure. The literature has commented extensively on defining IS project failure, recognising the many types of failure as defined in Lyytinen and Hirschheim (1987) and Standish Group (2013). However, the rational for defining IS project failure is not within the scope of this study as the case studies drawn from the literature in Hughes et al. (2017) have already established the project failure status.

We articulate a constructive critique and commentary on IRPs suitability and application to a range of contexts. This study aims to address the following questions:

1) Is the IRP methodologically rigorous in the context of its process and practical application within an IS project failure context?

2) Can the IRP method be easily scaled to complex problem scenarios whilst still maintaining its structural integrity?

3) Do the benefits of identifying dominating interactions with IRP, outweigh the inherent limitations of the method?

We position this study as a useful and timely contribution to the literature where the lived in experience and approach taken to extract best value from the method can potentially serve as a valuable and comprehensive aide memoir for future research using the IRP method. We present this paper as a comprehensive analysis and much needed methodological contribution to facilitating further analyzes and use of IRP within the academic community. The remaining content of this paper is structured around the following sections: Background and literature review, IRP methodology, Case study, Discussion and Conclusions. 


\section{Background and Literature Review}

Aspects of the literature have approached the topic of IS project success and failure through the lens of factor interrelationships identifying potential dominance of specific failure factors (FFs) and their impact on project outcomes (Belout and Gauvreau 2004, Delone and McLean 1992, 2003). More recent studies have extended this research to explore the interrelationships between IS project FFs applying a more structured and methodological approach using ISM (Hughes et al. 2016). However, although ISM provides a rigorous structured methodology for identifying contextual relationships (Dwivedi et al. 2017; Janssen et al. 2018, Kamble et al. 2019, Rana et al., 2019; Sushil, 2018), the standard application of the method does not facilitate any formal interpretation of dominance between sets of IS FFs (Hughes et al. 2017), thereby, limiting its application in specific contexts. The requirement for an interpretation of factor dominance is supported in a number of ISM related studies (Fawcett et al. 2008, Gunasekaran et al. 2004, Zhu et al. 2005). However, the literature has generally omitted to pursue a methodological approach to the identification of dominating interactions between FFs. The study by Hughes et al. (2017), attempted to fill this gap, with an examination of IS failure factors in the context of their dominating interactions within PRrojects In Controlled Environments (PRINCE2 ${ }^{\circledR}$ ) utilising IRP. The PRINCE2 ${ }^{\circledR}$ methodology is widely used within the UK public sector and has been extensively implemented within many private sector and educational organisations. The study posited valuable new insight to the dominance of IS project FFs within PRINCE2 ${ }^{\circledR}$ projects but omitted to present a deeper methodological critique of the IRP method.

IRP was developed by Professor Sushil in 2009 and positioned as an improved pairwise methodology over existing methods such as the Analytic Hierarchy Process (AHP). IRP is a structured matrix driven pairwise comparison method for ascertaining dominance between variables building on the strengths and limitations of intuitive and rational choice methods such as AHP. IRP can be applied in scenarios where a fixed number of variables or factors need to be ranked in order of dominance with relevance to a set of reference or performance variables. In the IRP context, experts are required to interpret and articulate the dominating interactions between the sets of variables. IRP does not require priori information on the extent of the dominance, as this is viewed to be subjective and problematic to interpret (Sushil 2009). To date, few studies have utilized the IRP method to identify the extent of dominance between factors; with the current body of IRP focused literature tending to focus exclusively on manufacturing and supply chain management (Haleem et al. 2012, Luthra et al. 2015, Mangla et al. 2014). These studies have successfully incorporated the methodology within their individual contexts, demonstrating the usefulness of the method to advance their hypotheses. However, the limited body of knowledge leaves many gaps and unanswered questions in the application of IRP. This fact has the potential to limit our further understanding and may be a barrier to utilisation of the method for future research. The method as presented in Sushil (2009) highlights the key steps in the process as well as a clear illustration and self-critique of the strengths and limitations of the method. However, as the author 
highlights the necessity of further scrutiny and validation of the method through further study and application, coupled with the limited number of papers that have referenced the method; it is clear that additional, more extensive research is required. Existing studies tend to provide a high level narrative on the implementation of the method, specific to their particular context or problem definition, but generally fail to provide any extensive feedback on the practical implementation of IRP (Haleem et al. 2012, Luthra et al. 2015, Mangla et al. 2014). This somewhat vanilla and lack of substantive analysis of IRP, has the potential to restrict further use of the method where researchers are not forearmed with the necessary empirically derived data to provide lessons learned on the methods limitations, strengths and suitability for their particular context.

The literature has sought to explore causal links and interdependencies between FFs contextualized by a specific problem narrative (Chander et al. 2013, Hughes et al. 2016, Salimifard et al. 2010). Research methods vary depending on context with studies relying on survey-supported data gathering, expert participant perspectives using methods such as Delphi and other studies selecting an alternative interpretive approach based on ISM (Agarwal, et al. 2007, Luthra et al. 2011, Thakkar et al. 2007). The literature highlights a number of instances where studies have identified either a requirement for the ranking of factors or where an implied ranking was performed based on participants perspectives or survey results (Fawcett et al. 2008, Gunasekaran et al. 2004, Zhu et al. 2005). The key observation from these studies and the wider literature is that in many instances, the concept of ranking is of strategic importance to the research context but the process by which the ranking based conclusions were reached is potentially subjective lacking a methodologically consistent approach throughout the literature.

The IRP method has been implemented in a limited number of studies namely: Haleem et al. (2012), Luthra et al. (2015) and Mangla et al. (2014) for the analysis of the interrelationships between Green Supply Chain (GSC) and manufacturing related factors respectively. Haleem et al. (2012) performed the first implementation utilising a linked ISM and IRP approach using a 10 x 10 matrix of factors. The study discusses the merits, limitations and comparisons between ISM and IRP in the context of method outputs articulating the case for the benefits of combining both approaches within a single implementation. However, although the study references the higher levels of complexity with larger matrix models, the limitations of IRP as stated in the study seem to replicate those stated in Sushil (2009), lacking any substantive additional observations and lived in feedback in the use of the method. The inherent complexity and difficulty in representing a non-trivial interpretive ranking model as set out in Haleem et al. (2012), demonstrates the systematic difficulties in presenting the dominance relationships diagrammatically for larger matrix sized problems.

Risk mitigation strategies for GSC were studied by Mangla et al. (2014), where the implementation utilised a Situation Actor Process-Learning Action Performance (SAPLAP) method linked with IRP to present a new flexible framework. The study justified 
the approach of using SAP-LAP in conjunction with IRP to mitigate some of the perceived limitations of SAP-LAP in the context of validity and transparency. The research presented a $5 \times 4$ matrix problem thereby minimizing complexity and highlighted the role and commitment of top management in the development of GSC risk mitigation strategies (Mangla et al. 2014). The study omitted to reflect on the application of IRP in the context of the specific limitations and benefits for this research, choosing to reference those stated in Sushil (2009) rather than exploring these areas contextualized for the use of SAP-LAP and IRP. Furthermore, although the study references the use of experts in describing the steps of IRP, little further clarity is offered to articulate the expert composition and reflection for this research; particularly as highlighted in this study the fact that IRP requires increased levels of expert contribution over methods such as ISM. The research outlined in Luthra et al. (2015) explores GSC management factors relating to sustainability within the Indian automobile industry. The study highlights the limited discussion within the literature on IRP and presented a narrative for selection of the method highlighting the inability of ISM to consider dominance in the interpretive interactions. The problem definition within Luthra et al. (2015) was condensed to a $6 \times 4$ matrix problem via participant survey and factor analysis. The study avoided the potential for subjective bias on the part of the academic and industrial sourced experts in the population of the cross interaction matrix by incorporating a questionnaire to elicit interpretations on factor dominance. The pair wise comparison element in the IRP process was facilitated via a workshop approach involving seven expert participants from academia and industry to develop a consensus on the dominating interactions between the factors. The Luthra et al. (2015) study reflects on the use of the method, concluding that IRP is inherently more complex than associated interpretive based methods such as ISM and makes the case for IRP delivering qualitatively better and more realistic results than ISM (Luthra et al. 2015). The final point here seems somewhat subjective in that these conclusions cannot be easily validated from the results of the study and perhaps should be qualified as such in the findings.

The conclusion drawn from the review of the existing literature, is that studies have to date omitted to present an extensive substantive analysis of the lived in experience of implementing IRP. The limited number of existing studies that have utilized IRP, in our view - generally tend to opt for a vanilla implementation of the method refraining from a full critique of the process contextualized for their specific factor dominance related problems. This seems to be a significant gap in the literature, highlighting the necessity for further study to provide more substantive analysis of the real world practical application of the method and usefulness for further academic analysis.

\section{IRP Method}

In this section we analyze the IRP method in detail outlining the key steps in the process and articulating some of the intricacies of its implementation. The key steps in the IRP process are highlighted in figure 1. 
Fig 1: IRP Process (Source: adapted from Sushil 2009)

Central to the method is the use of experts to interpret the relationships between the variables: "In IRP, the expert is supposed to spell out the interpretive logic for the dominance of one element over the other for each paired comparison" (Sushil 2009, pp. 2). However, although Sushil (2009) makes clear that the implementation of IRP requires expert participation, the extent of this input is not explicit from the paper. This seems to be an omission given that IRP requires a greater degree of expert participation than established interpretive methods such as ISM and is a critical integral component in the process. Sushil (2009) does not indicate the advocated number of experts required, nor the ideal makeup of the expert group in the context of industry or academia; leaving the researcher to decide on these factors based on their specific implementation. Although the paper illustrates a case study example namely - ABB India as a useful example of the implementation of the method, the use of experts is not explicitly referenced in this section. Under the title: Cross Validation of Dominance - Sushil (2009, pp 6-7) highlights the options of cross validation and states that researchers can: "obtain interpretations from more than one expert and the rankings obtained can be cross checked." It is not clear from these statements if this implies that a single expert will suffice for IRP and by inference an additional expert can be used to cross check the rankings, or if this refers to an expert group. Researchers proposing to use IRP could benefit from greater clarity on the advised expert composition or any numerical validity constraints that would aid implementation.

Sushil has identified a number of validation points in the paper and positioned these in the context of building confidence in the IRP model. These are illustrated in figure 1. The interpretive nature of the method necessitates that researchers are advised to facilitate structured walkthroughs of the cross interaction and cross interaction interpretive matrices to ensure data consistency and interpretation accuracy. Further checks on the dominance relationships can be actioned by the generation of digraphs to validate the single-direction of flow and lack of feedback loop in the system. Cross validation of the dominance matrix can be accomplished by summing the net dominance figures in the matrix to ensure they equal zero, and potentially incorporating the views of additional experts. Sushil also recommends a real life implication check on the ranking output of the method to provide a final sanity check on the results to assure their contextual validity.

Sushil identifies a number of limitations for IRP and acknowledges that the 2009 paper is positioned as a first attempt and that many of the concepts are presented for further scrutiny rather than exhaustively detailed to keep within manageable limits of comprehension for this initial study. The paper acknowledges the subjectivity of the method as a key limitation in that IRP relies on interpretive and potentially judgmental 
processes where expert participants are required to reach a consensus on dominating interactions between variables. The paper further acknowledges limitations of IRP in the context of: treating all criteria equally (although weightings can be used), objective validation tests and inherent complexities when incorporating matrix sizes greater than 10x10 thereby, limiting the method to modest sized problems. In our analysis of the method we would also highlight that the method is somewhat limited by the complexities of attaining consensus amongst a modest sized expert participant group especially in the context of a problem requiring the population and validation of problems approaching the $10 \times 10$ recommended matrix limit. Furthermore, the interpretive ranking model as presented in the paper is based on a simple $4 \times 4$ matrix and as such ensures the final model as presented is readable. Larger models approaching the recommended matrix limit can in our view be overly complex, as presented in Haleem et al. (2012), perhaps negating their usefulness and ability to be interpreted correctly. The strengths of the IRP method as defined in Sushil 2009 are:

- based on strength of pairwise comparison,

- $\quad$ simplicity of ascertaining dominance between factors

- ease of comparison and identification of interaction impact,

- not reliant on criteria weighting,

- ability to rank varied sets of factors,

- ability to for process to accommodate multiple interest groups in the evaluation,

- implementation of method does not require any complex resources

The method process claims to not create any cognitive overload which seems somewhat subjective in that depending on the size of the problem and therefore the matrix used, together with the composition of experts, cognitive overload could be a factor. However, based on our experience of implementing the method, the skills and experience of the researcher/facilitator can help to mitigate potential cognitive overload issues. The method although not dependent on any specific software resources, benefits in our view from an implementation utilising a structured spreadsheet format for each of the matrix stages to aid visualization and automate validation checks. The ease of deciding on the dominance of one interaction over the other, although stated as "comparatively easy" in Sushil (2009); in our specific implementation this proved to be problematic in certain instances where at times the dominance was extensively debated amongst the expert participants until a consensus was reached. This proved to be time consuming.

\section{Case Study Example}

The case study example utilised for this study is based on Hughes et al. (2017). The Hughes et al paper was selected as the study presented a somewhat complex application of the IRP method, thereby offering a significant test of an IRP implementation. The Hughes et al research although demonstrating an application of IRP, omitted to offer a formal critique and assessment of the usefulness of the methodology. The relatively small number of studies within the literature that have utilised IRP, highlights the 
necessity for an objective critique of the method to inform researchers on its application and suitability for future research projects. The main objective of the Hughes et al paper is the identification of the key dominating interactions and interdependencies between FFs within PRINCE $2^{\circledR}$ project stages. The study supports aspects of the IS failure literature in the futility of a prevention narrative (Sitkin 1992). This approach emphasises the criticality of preventing catastrophic failure, whilst embracing the reality that IS projects are likely to experience some degree of failure throughout the lifecycle (Hughes et al. 2017).

The Hughes et al study presented an IRP implementation and was the first to utilise this method for this specific context and application. The ten factors (A1 - A10) were selected from the IS failure literature (Table 1) and ten additional variables (Table 2) were agreed by the expert participants to function as the performance variables (P1 P10). The IRP method prescribes that the two sets of factors (A1-10 and P1-10) are processed using a pairwise comparison process where the expert participants are asked to express their views on the dominating relationships between each within a matrix form. The expert participants selected for the Hughes et al study are IS practitioners drawn from: public sector health authority, government agency and finance industries. All had extensive experience within their respective industry sectors exhibiting a tacit knowledge of IS projects within structured environments and industrial sectors (Hughes et al. 2017).

Table 1. List of project failure factors (Source: adapted from Hughes et al. 2017)

In IRP terms, the problem definition within the case study required a $10 \times 10$ construct (A1-A10 x P1-P10) necessitating an interpretation of a separate matrix at each stage to cater for the full PRINCE2 ${ }^{\circledR}$ lifecycle. This resulted in a $4 \times(10 \times 10)$ problem as the IRP methodology needed to be applied four times, once for each of the four PRINCE2 ${ }^{\circledR}$ stages.

Table 2: List of performance factors (Source: adapted from Hughes et al. 2017)

The rational within the Hughes et al study for this specific implementation of IRP, is a requirement to validate the hypotheses that FFs and the dominating interactions therein, could impact the project at key stages in the PRINCE2 ${ }^{\circledR}$ project lifecycle. Figure 2 highlights the IRP application context across each of the mandatory PRINCE2 ${ }^{\circledR}$ stages.

Figure 2: IRP method applied to PRINCE2 ${ }^{\circledR}$ Stages (Source: adapted from Hughes et al. 2017) 
As the IRP scenario illustrated in figure 2 is a $4 \times(10 \times 10)$ problem, the IRP process is repeated for each of the four PRINCE2 $®$ stages. As highlighted in Figure 1 - the final ranking is developed from the net instances of number of dominating (D) and number being dominated (B) using the equation:- Rank = D-B. The number of dominating (D) and number being dominated (B) notation is referenced in step 6 within the IRP process (Figure 1) and refers to the pairwise comparison and views from the expert participants on the dominating interactions between the factors. The results for this process from Hughes et al. are highlighted in Table 3 where the factor ranking is denoted.

Table 3: Final IRP ranking for FFs against each stage (Source: adapted from Hughes et al. 2017)

The rank dominance for each FFs is listed in the final column of the matrices and denoted in the form I - X. "I" signifies the highest level of ranking and "X" the least significant ranking for the set of FFs. Validation of the results was performed via a simple zero summation check of the net dominance column in each of the dominance matrices. A structured walk through was undertaken to validate the final matrix data against the previous matrices in the model. The final step in the IRP method - namely the development of the interactive ranking model, was deemed in the Hughes et al study to be nugatory additional work, partly due to the complexity in diagrammatically presenting the $4 \times(10 \times 10)$ matrix problem and the fact that the populated dominance matrices present the final rank dominance for each of the factors. However, it is acknowledged that for non-complex IRP implementations such as the IRP example setout in Mangla et al. (2014), the interactive ranking model is a useful visual representation of the dominating interactions.

\section{Discussion}

The specific implementation of IRP as highlighted in the selected case study, could be viewed as a complex example as it necessitated a $4 \times(10 \times 10)$ matrix problem. However, the justification of its inclusion is primarily on the basis of offering an objective critique of an IRP implementation where the method has been applied to the limits of its capability in the chosen context. The case study example demonstrates the structured process inherent within IRP and the methodological interpretive approach to identify dominance within factor relationships. However, the Hughes et al study failed to offer any meaningful critique of the implementation of the IRP method. By drawing from the case study, we are able to highlight a number of strengths and weaknesses from the implementation of the method. These are outlined below and are a corroboration of some of the points listed in Sushil (2009) and Luthra et al. (2015) together with additional observations from the research presented in Hughes et al. (2017). The strengths and weaknesses of the IRP method based are presented in table 4 . 
Table 4: IRP strengths and Weaknesses.

\subsection{Reflections on the use of IRP}

Researchers opting to apply the method would benefit from greater clarity on the structure and extent of expert participation. Although the method references these aspects in parts, the process would benefit from a more explicit set of guidance to reduce uncertainty and extract maximum benefit from implementation. This could be elucidated by defining a minimum number of expert participants required to assure validity and consistency and provide clarity on the stages in the method that require expert input (Figure 1). The concept of expressing dominance between variables specific to the interaction with performance variables and not directly with each other is a non-trivial concept to express to an expert group. There is a risk that this aspect of the process could perhaps not be fully understood by the expert participants and therefore, has the potential to incorrectly influence the interpretations of dominant interactions. This specific point has been covered in Sushil (2009) but in our view requires greater clarity to provide researchers with a more descriptive or diagrammatical explanation. The development of the interpretive ranking model as defined in Sushil (2009) is defined as a formal step in the process, whereas this step is an optional stage as the rankings have already been defined in the dominance matrix. This step should in our view be identified as discretionary that may provide greater clarity for small matrix problems. Studies processing larger matrices are likely to spend a not inconsiderate amount of time developing this step with (in our view) negligible benefit due to the visual complexity in presenting large matrix problems. Evaluating reviewing research question 1) Is the IRP methodologically rigorous in the context of its process and practical application within an IS project failure context? Although the IRP process has its limitations, we conclude that the IRP process is rigorous within an IS project failure context, as its is able to demonstrate the dominating relationships between the key factors via a methodologically thorough process.

With reference to research question 2) Can the IRP method be easily scaled to complex problem scenarios whilst still maintaining its structural integrity? and research question 3) Do the benefits of identifying dominating interactions with IRP, outweigh the inherent limitations of the method? These questions refer to the ability of the method to retain its rigour and suitability as it is scaled to greater levels of problem complexity and the assessment of benefits outweighing methodological limitations. The key inherent limitation of the method in its inability to cater for problems of matrix sizes greater than $10 \times 10$ due to the required processing complexity may mean that researchers reject the method due to this single constraint. The structured process followed by Luthra et al. (2015) in the condensing of factors, could be a pertinent addition to the IRP method that could enhance its practical application to a greater range of scenarios providing that the methodology used to reduce the variable set is rigorous. We conclude that the benefits of the IRP process outweigh the stated limitations and scalability is possible whilst 
retaining methodological integrity. However, with scalability we assert complexity is also increased in the context of the application of the method.

\subsection{Theoretical Contribution}

This study sets out to further the existing limited research on the IRP method to provide a more extensive and informed narrative on its application and suitability for interpretation of factor dominance. The method as presented in Sushil (2009), although establishing the theoretical groundwork, process and potential application, has not, we suggest been subjected to substantive evaluation and critique within the wider academic community. The existing IRP focused literature whilst demonstrating applications of the method, generally falls short in offering new insight on the strengths and weaknesses of the method over those stated in Sushil (2009). The literature has generally approached the topic of factor ranking inconsistently, with many studies approaching the problem from different perspectives (Fawcett et al. 2008, Gunasekaran et al. 2004, Zhu et al. 2005) relying upon participants to express their views on factors interrelationships based on survey results or interviews, perhaps we suggest, lacking a more formal structured methodological interpretive based approach. This study is presented as valuable research to fill this gap and present a more substantive theoretical contribution via an extensive critique of IRP that documents the key findings and recommendations for further application.

This study offers the academic community valuable feedback and insight in the application of IRP highlighting many of the benefits and drawbacks of the process. The implementation of IRP is non-complex and follows a step-by-step approach where the results of each stage are processed in turn toward the final ranking. The method has a number of validation points that can be used to cross check the results as the process evolves. This ensures that researchers can easily assure the integrity of the results at each step. The visual matrix driven approach that underscores the method requiring minimal priory knowledge to understand the process and implementation, highlights the ease by which the IRP interim results can be easily validated. Although IRP is methodologically rigorous requiring the implementation of a structured process, the application of the method does not require significant mathematical complexity or prior understanding of mathematical concepts.

Although the IRP method has been limited to an academic context to date, the method could be used in practice to offer a rigorous methodological approach to ascertaining dominance between factors. The suggested improvements to the method outlined in this study would help in this regard, especially the greater clarity of expert contribution and composition during the initial steps.

\section{Conclusions}

The IRP method as outlined in Sushil (2009) has to date failed to engender a critical mass of adoption within the literature in the context of further analysis or critical appraisal. This seems somewhat surprising as the method seems to be suited to a number 
of different applications where the interpretation of dominance between factors is required via a structured methodological approach. To date a relatively small number of studies have referenced the method (Haleem et al. 2012, Luthra et al. 2015, Mangla et al. 2014). These existing studies tend to provide a high level narrative on the use of the method, but generally we assert, are lacking in substantive feedback on the practical implementation of IRP. We hypothesize that this lack of extensive analysis has constrained further empirically derived study aimed at identifying additional contextual strengths and weaknesses specific to implementation scenarios. We have specifically set out to critique the application of IRP to a non-trivial scenario that we posit; tests the method to the limits of its application by implementing a 4x(10x10) matrix problem.

The case study based on Hughes et al. (2017) demonstrates an instance of the application of IRP within an IS project failure context and highlights the potential of its usefulness in this context but also in a number of areas where there exists a requirement to ascertain dominance between factors. IRP is not without its drawbacks and our findings have highlighted some of the strengths and weaknesses of the method along with a number of recommendations for improvement over and above those referenced in Sushil (2009) and subsequent studies (Haleem et al. 2012, Luthra et al. 2015, Mangla et al. 2014). The findings highlight the inherent constraints of implementing the method namely: lack of clarity in some of the steps within the process and scaling for larger more complex problems greater than matrix size - 10x10. However, our study highlights via an empirically derived IS failure factor implementation of the method, that IRP is flexible enough to be scaled to cover non-trivial scenarios requiring a $4 \times(10 \times 10)$ matrix problem. In our view the method has potential to be utilised in a number of different contexts where factor dominance is required. We position this study as a valuable contribution to the literature where the lived in experience and practical empirically driven approach to extract best value from the method can potentially serve as a driver for future studies using IRP. We present these findings to the wider research community and advocate further research utilizing the IRP method to critique the conclusions set out in this paper and extend the existing knowledgebase.

The study is limited by the reliance on a single case study to demonstrate a representative implementation of IRP. Additional scrutiny and validation of the method could be applied by incorporating a second study to validate the findings and conclusions drawn. The research is also limited by the selection of a complex problem in that although this enables the testing of the method to its practical extremes, perhaps omits a number of key considerations and more realistic appraisal of benefits that would be apparent in a more pragmatic application of the method. More extensive research is recommended using a range of ranking scenarios that could extend the implementation of IRP and further refine the method for the wider research community. 


\section{References}

Aladwani, A. M. (2016). Corruption as a source of e-Government projects failure in developing countries: A theoretical exposition. International Journal of Information Management, 36(1), 105-112.

Agarwal, A., Shankar, R., and Tiwari, M.K. (2007). Modeling agility of supply chain. Industrial Marketing Management, 36(4), 443-457.

Aranyossy, M., Blaskovics, B., \& Horváth, Á. A. (2017). How universal are it project success and failure factors? evidence from hungary. Information Systems Management, available at http://www.tandfonline.com/doi/full/10.1080/10580530.2017.1416943

BBC 2017a. Accessed on 01.05.2017. "Home Office criticized over $£ 830 \mathrm{~m}$ 'failed' borders scheme," http://www.bbc.co.uk/news/uk-34988913

BBC 2017b. Accessed on 01.05.2017. "BBC was complacent over failed $£ 100 \mathrm{~m}$ IT project," http://www.bbc.co.uk/bbctrust/news/press_releases/2013/pwc_dmi.html

BBC 2017c. Accessed on 01.05.2017. "NHS IT system one of 'worst fiascos ever', say MPs," http://www.bbc.co.uk/news/uk-politics-24130684.

Belout, A. and Gauvreau, C., (2004). Factors influencing project success: the impact of human resource management. International Journal of Project Management, 22(1), 1-11.

Beynon-Davies, P. (1995) Information systems "failure": the case of the London Ambulance services Computer Aided Despatch project. Proceedings of the 3rd European Journal of Information Systems, 4(3),171-184.

Chander, M., Jain, S.K., Shankar, R. (2013). Modeling of information security management parameters in Indian organizations using ISM and MICMAC approach, Journal of Modelling in Management, 8(2), 171 - 189.

Computer Weekly (2018). TSB IT meltdown has the makings of an epic. Accessed on $6^{\text {th }}$ August 2019.https://www.computerweekly.com/news/252439859/TSB-IT-meltdown-hasthe-makings-of-an-epic

Cule, P., Schmidt, R., Lyytinen, K., \& Keil, M. (2000). Strategies for heading off is project failure. Information Systems Management, 17(2), 65-73.

DeLone, W.H. and McLean, E.R., (2003). The DeLone and McLean model of information systems success: a ten-year update. Journal of Management Information Systems, 19(4), 930 .

DeLone, W.H. and McLean, E.R., (1992). Information systems success: The quest for the dependent variable. Information Systems Research, 3(1).60-95.

Dwivedi, Y. K., Janssen, M., Slade, E. L., Rana, N. P., Weerakkody, V., Millard, J., ... \& Snijders, D. (2017). Driving innovation through big open linked data (BOLD): Exploring antecedents using interpretive structural modelling. Information Systems Frontiers, 19(2), 197-212.

Dwivedi YK, Wastell D, Laumer S, Henriksen HZ, Myers MD, Bunker D, Elbanna A, Ravishankar MN, Srivastava SC (2015) Research on Information Systems Failures and Successes: Status Update and Future Directions. Information Systems Frontiers, 17(1), 143-157. 
Fawcett, S.E., Magnan, G.M. and McCarter, M.W. (2008). Benefits, barriers, and bridges to effective supply chain management, Supply Chain Management: An International Journal, 13(1), 35-48.

Goldfinch, S., (2007). Pessimism, computer failure, and information systems development in the public sector. Public Administration Review, 67(5), 917-929.

Gunasekaran, A., Patel, C. and McGaughey, R.E. (2004). A framework for supply chain performance measurement, International Journal of Production Economics, 87(3), 333347.

Haleem, A., Sushil, M. A. Qadri and S. Kumar. (2012). Analysis of critical success factors of world-class manufacturing practices: an application of interpretative structural modelling and interpretative ranking process, Production Planning \& Control, 23(10-11), 722-734.

Hughes, D.L., Dwivedi, Y.K., Simintiras, A.C. and Rana, N.P., 2015. Success and Failure of IS/IT Projects: A State of the Art Analysis and Future Directions. Springer. Heidelberg.

Hughes, D.L., Y. K. Dwivedi, A. C. Simintiras and N. P. Rana. (2016). Information systems project failure-analysis of causal links using interpretive structural modelling, Production Planning \& Control, 27(16), 1-21.

Hughes, D. L., Dwivedi, Y. K., \& Rana, N. P. (2017). Mapping IS failure factors on PRINCE2 ${ }^{\circledR}$ stages: An application of interpretive ranking process (IRP). Production Planning \& Control, 28(9), 776-790.

Janssen, M., Rana, N. P., Slade, E. L., \& Dwivedi, Y. K. (2018). Trustworthiness of digital government services: deriving a comprehensive theory through interpretive structural modelling. Public Management Review, 20(5), 647-671.

Kamble, S. S., Gunasekaran, A., \& Sharma, R. (2019). Modeling the blockchain enabled traceability in agriculture supply chain. International Journal of Information Management. DoI: https://doi.org/10.1016/j.ijinfomgt.2019.05.023

Kappelman, L. A., McKeeman, R., \& Zhang, L. (2006). Early warning signs of IT project failure: The dominant dozen. Information Systems Management, 23(4), 31-36.

Luthra, S., Kumar, V., Kumar, S. and Haleem, A. (2011). Barriers to implement green supply chain management in automobile industry using interpretive structural modeling technique: An Indian perspective, Journal of Industrial Engineering and Management, 4(2), 231-257.

Luthra, S., Garg, D. and Haleem, A. (2015). Critical success factors of green supply chain management for achieving sustainability in Indian automobile industry, Production Planning \& Control, 26(5), 339-362.

Lyytinen, K., \& Hirschheim, R. (1987). Oxford surveys in information technology. New York, NY, USA: Oxford University Press, Inc, 257-309.

Malaurent, J., \& Avison, D. (2015). From an apparent failure to a success story: ERP in China-Post implementation. International Journal of Information Management, 35(5), 643-646.

Mangla, S.K., Kumar, P. and Barua, M.K. (2014). A flexible decision framework for building risk mitigation strategies in green supply chain using SAP-LAP and IRP approaches, Global Journal of Flexible Systems Management, 15(3), 203-218. 
Martinsons, M. G., Davison, R. M., \& Huang, Q. (2017). Strategic knowledge management failures in small professional service firms in China. International Journal of Information Management, 37(4), 327-338.

McComb, D., \& Smith, J. Y. (1991). System project failure: the heuristics of risk. Information System Management, 8(1), 25-34.

Meade, L. M., \& Sarkis, J. (1999). Analyzing organizational project alternatives for agile manufacturing processes: an analytical network approach, International Journal of Production Research, 37(2), 241-261.

Mitev N.N. (1996) More than a failure? The computerized reservation systems at French Railways. Information Technology \& People 9(4), 8-19.

Murray, J. P. (2001). Recognizing the responsibility of a failed information technology project as a shared failure. Information Systems Management, 18(2), 25-29.

Pan, G., Hackney, R., \& Pan, S. L. (2008). Information Systems implementation failure: Insights from prism. International Journal of Information Management, 28(4), 259-269.

Park, J. H., Kim, Y. B., \& Kim, M. K. (2017). Investigating factors influencing the market success or failure of IT services in Korea. International Journal of Information Management, 37(1), 1418-1427.

Peterson, D. K., Kim, C., Kim, J. H., \& Tamura, T. (2002). The perceptions of information systems designers from the United States, Japan, and Korea on success and failure factors. International Journal of Information Management, 22(6), 421-439.

Rana, N. P., Barnard, D. J., Baabdullah, A. M., Rees, D., \& Roderick, S. (2019). Exploring barriers of $\mathrm{m}$-commerce adoption in SMEs in the UK: Developing a framework using ISM. International Journal of Information Management, 44, 141-153.

Salimifard, K., Abbaszadeh, M. A., \& Ghorbanpur, A. (2010). Interpretive structural modeling of critical success factors in banking process re-engineering, International Review of Business Research Papers, 6(2), 95-103.

Saxena, J. P., \& Vrat, P. (1992). Scenario building: a critical study of energy conservation in the Indian cement industry, Technological Forecasting and Social Change, 41(2), 121-146.

Singh, M. D., Shankar, R., Narain, R., \& Agarwal, A. (2003). An interpretive structural modeling of knowledge management in engineering industries. Journal of Advances in Management Research, 1(1), 28-40.

Sitkin SB (1992) Learning through failure: The strategy of small losses. Research in Organizational Behaviour, 14, 231-266.

Standish Group. 2013. CHAOS MANIFESTO Think Big Act Small. Boston.

Standish Group. 2015. CHAOS MANIFESTO. Boston.

Sushil. (2018). Incorporating polarity of relationships in ISM and TISM for theory building in information and organization management. International Journal of Information Management, 43, 38-51.

Sushil (2009). Interpretive Ranking Process, Global Journal of Flexible Systems Management, 10, 1-10.

Thakkar, J., Kanda, A., \& Deshmukh, S. G. (2007). Evaluation of buyer-supplier relationships using an integrated mathematical approach of interpretive structural modeling (ISM) and graph theoretic matrix: the case study of Indian automotive SMEs, Journal of Manufacturing Technology Management, 19(1), 92-124. 
Zhu, Q., Sarkis, J. and Geng, Y. (2005). Green supply chain management in China: pressures, practices and performance. International Journal of Operations \& Production Management, 25(5), 449-468.

\section{Appendix}

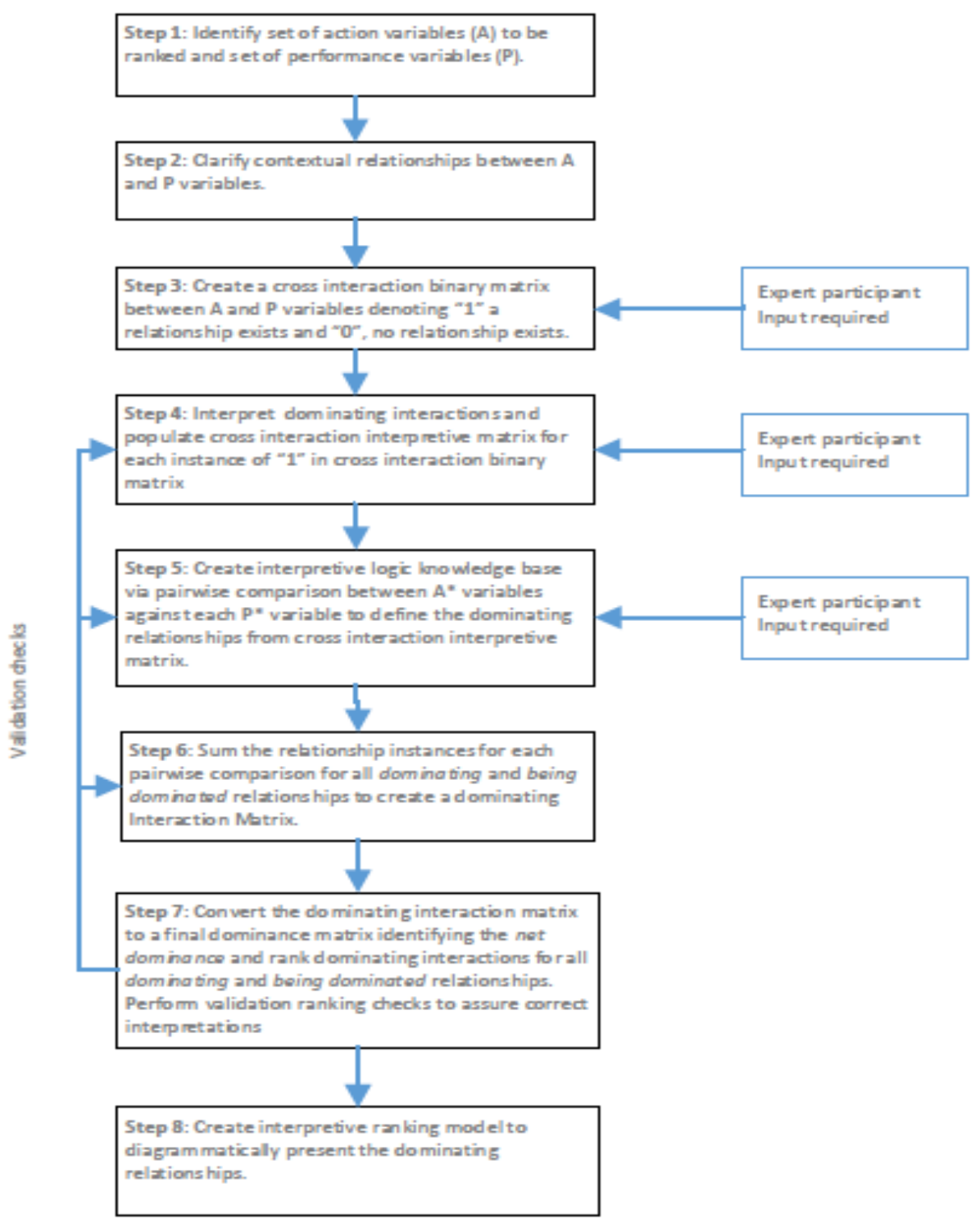

Figure 1: IRP Process (Source: adapted from Sushil 2009)

Table 1. List of project failure factors (adapted from Hughes et al. 2017)

\begin{tabular}{|l|l|}
\hline Failure Factor & Description \\
\hline $\begin{array}{l}\text { A1. Breakdown in } \\
\text { relationship between external }\end{array}$ & $\begin{array}{l}\text { Issues relating to the relationship between the organisation itself } \\
\text { and the external supplier contracted to supply either human capital, }\end{array}$ \\
\hline
\end{tabular}




\begin{tabular}{|l|l|}
\hline contractor and organisation & $\begin{array}{l}\text { expertise or services in the form of software or IS products as part } \\
\text { of project scope. }\end{array}$ \\
\hline $\begin{array}{l}\text { A2. Inadequate project } \\
\text { sponsorship }\end{array}$ & $\begin{array}{l}\text { Factors relating to the impact on the project from poor project } \\
\text { sponsorship and commitment to the project from senior } \\
\text { management. }\end{array}$ \\
\hline A3. Poor business case & $\begin{array}{l}\text { Inadequate or poorly constructed business case with resulting } \\
\text { negative impact on perceived benefits and financial integrity of } \\
\text { project. }\end{array}$ \\
\hline A4. Poor staff Performance & $\begin{array}{l}\text { Impact on project due to poor performance of project team and/or } \\
\text { key stakeholders. }\end{array}$ \\
\hline $\begin{array}{l}\text { A5. Insufficient audit and } \\
\text { mortem process }\end{array}$ & $\begin{array}{l}\text { Poor audit process and inability of organisation to learn } \\
\text { lesson of previous projects. }\end{array}$ \\
\hline $\begin{array}{l}\text { A6. Size and complexity of } \\
\text { project }\end{array}$ & $\begin{array}{l}\text { Issues directly relating to project size and complexity and the } \\
\text { inherent issues in formally managing and delivering to large } \\
\text { budgets and long lead times. }\end{array}$ \\
\hline A7. Poor project management & $\begin{array}{l}\text { Failure related to the skills, experience and style of the project } \\
\text { manager in the delivery and benefits realization of the project. }\end{array}$ \\
\hline $\begin{array}{l}\text { A8. Poor requirements and } \\
\text { management }\end{array}$ & $\begin{array}{l}\text { Inadequate or poorly constructed requirements definition } \\
\text { and scope management. }\end{array}$ \\
\hline A9. Poor communication & $\begin{array}{l}\text { Lack of formal stakeholder communication process and } \\
\text { mechanisms resulting in project failure. }\end{array}$ \\
\hline $\begin{array}{l}\text { A10. Poor change } \\
\text { management }\end{array}$ & $\begin{array}{l}\text { Poorly managed organisational change resulting in low } \\
\text { levels of adoption and benefits realization. }\end{array}$ \\
\hline
\end{tabular}

Table 2: List of performance factors (Source: adapted from Hughes et al. 2017)

\begin{tabular}{|c|c|}
\hline Performance Factors (p) & Description \\
\hline $\begin{array}{l}\text { P1. Full engagement and committed project } \\
\text { sponsorship } \\
\text { from executive }\end{array}$ & $\begin{array}{l}\text { Senior management are fully committed to the } \\
\text { project and are able to drive the initiative forward. }\end{array}$ \\
\hline $\begin{array}{l}\text { P2. Adequate user involvement throughout the } \\
\text { project }\end{array}$ & $\begin{array}{l}\text { Users are an integral part of the project team from } \\
\text { the onset and continue to be closely coupled with } \\
\text { the project throughout the lifecycle. }\end{array}$ \\
\hline $\begin{array}{l}\text { P3. Suitable Skills, experience and style of project } \\
\text { Manager }\end{array}$ & $\begin{array}{l}\text { The appointed project manager possesses the } \\
\text { required experience, capability and management } \\
\text { style for the project and the organisation. }\end{array}$ \\
\hline P4. Optimized project scope & $\begin{array}{l}\text { The project and organisation has a formal process i } \\
\text { place that ensures risk, timescales, business case } \\
\text { and benefits are all factored into scope changes. }\end{array}$ \\
\hline P5. Clear business objectives & $\begin{array}{l}\text { The project justification is structured around clear } \\
\text { business benefits to the organisation. }\end{array}$ \\
\hline $\begin{array}{l}\text { P6. Effective project maturity and established } \\
\text { processes }\end{array}$ & $\begin{array}{l}\text { The organisation has established structures and } \\
\text { processes to engender a suitable project culture and } \\
\text { delivery framework. }\end{array}$ \\
\hline P7. Short stage duration (less than one year) & $\begin{array}{l}\text { Project plans are structured to organize the } \\
\text { project deliverables within short duration stages } \\
\text { to ensure adequate control is exercised by the } \\
\text { senior management team. }\end{array}$ \\
\hline
\end{tabular}




\begin{tabular}{|l|l|}
\hline P8. Effective benefits management process & $\begin{array}{l}\text { Project benefits are clearly identified within the } \\
\text { business case and formally managed through to } \\
\text { realization. }\end{array}$ \\
\hline P9. Integrated change and project management & $\begin{array}{l}\text { Change and project management are integrated } \\
\text { early in the project lifecycle and fully supported } \\
\text { by senior management. }\end{array}$ \\
\hline $\begin{array}{l}\text { P10. Established project Audit \& post mortem } \\
\text { process }\end{array}$ & $\begin{array}{l}\text { Lessons learned from previous projects is a } \\
\text { formalized process and periodic audits are } \\
\text { undertaken throughout key stages of the project } \\
\text { reporting to senior management. }\end{array}$ \\
\hline
\end{tabular}

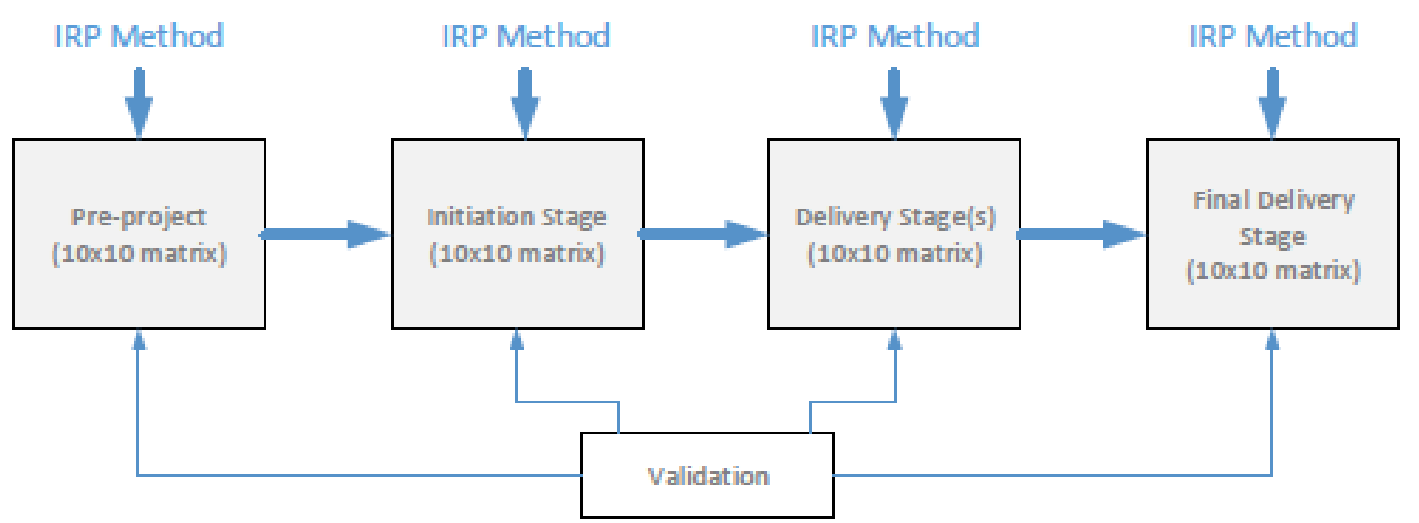

Figure 2: IRP method applied to PRINCE $2{ }^{\circledR}$ Stages (Source: Hughes et al. 2017)

Table 3: Final IRP ranking for FFs against each stage (Source: Source: adapted from Hughes et al. 2017)

\begin{tabular}{|c|c||c|c||c|c||c|c|c|}
\hline & \multicolumn{2}{|l|}{ Pre-project stage } & \multicolumn{2}{c|}{ Initiation Stage } & \multicolumn{2}{c|}{ Delivery Stage(s) } & \multicolumn{2}{c|}{ Final Delivery Stage } \\
\hline & $\begin{array}{c}\text { Net } \\
\text { Dominance } \\
\text { (D-B) }\end{array}$ & $\begin{array}{c}\text { Rank } \\
\text { Dominance }\end{array}$ & $\begin{array}{c}\text { Net } \\
\text { Dominance } \\
\text { (D-B) }\end{array}$ & $\begin{array}{c}\text { Rank } \\
\text { Dominance }\end{array}$ & $\begin{array}{c}\text { Net } \\
\text { Dominance } \\
\text { (D-B) }\end{array}$ & $\begin{array}{c}\text { Net } \\
\text { Rank } \\
\text { Dominance }\end{array}$ & $\begin{array}{c}\text { Dominance } \\
\text { (D-B) }\end{array}$ & $\begin{array}{c}\text { Rank } \\
\text { Dominance }\end{array}$ \\
\hline A1 & -10 & VI & -25 & VIII & -28 & VIII & -30 & IX \\
\hline A2 & 15 & I & -10 & VII & -31 & IX & -17 & VI \\
\hline A3 & -9 & V & 32 & I & 12 & V & 7 & IV \\
\hline A4 & -9 & V & -28 & IX & -42 & X & -38 & X \\
\hline A5 & 15 & I & -6 & VI & -21 & VII & -21 & VII \\
\hline A6 & 3 & III & 17 & IV & 23 & III & 4 & V \\
\hline A7 & -7 & IV & 20 & III & 52 & I & 42 & II \\
\hline A8 & -7 & IV & 22 & II & 33 & II & 29 & III \\
\hline A9 & 3 & III & -28 & IX & -13 & VI & -23 & VIII \\
\hline A10 & 6 & II & 6 & V & 15 & IV & 47 & I \\
\hline
\end{tabular}


Table 4: IRP strengths and Weaknesses.

\begin{tabular}{|c|c|}
\hline IRP Strengths & IRP Weaknesses \\
\hline $\begin{array}{l}\text { Pairwise comparison process of } \\
\text { ascertaining dominance between factors } \\
\text { is structured and non-complex. }\end{array}$ & $\begin{array}{l}\text { Potential significant workload (dependent on } \\
\text { problem complexity) and subsequent reliance on } \\
\text { experts for number of steps in the model; greater than } \\
\text { other interpretive methods such as ISM. }\end{array}$ \\
\hline $\begin{array}{l}\text { Knowledge of the extent of dominance is } \\
\text { not necessary, thereby reducing } \\
\text { workload from expert participants. }\end{array}$ & $\begin{array}{l}\text { Lack of clarity on recommended structure or number } \\
\text { of experts required and guidance on process of } \\
\text { working with experts to process through the } \\
\text { matrices. }\end{array}$ \\
\hline $\begin{array}{l}\text { Offers a more rigorous methodology } \\
\text { than alternative options that rely } \\
\text { exclusively on participant perspectives } \\
\text { of interrelationships between factors. }\end{array}$ & $\begin{array}{l}\text { to cater for larger more complex problems - } \\
\text { than matrices of } 10 x 10 \text { due to interpretive } \\
\text { ad required to process problems of this size. } \\
\text { omewhat limits the method to more modest } \\
\text { roblems. }\end{array}$ \\
\hline $\begin{array}{l}\text { nge of } \\
\text { by a }\end{array}$ & $\begin{array}{l}\text { of the } \\
\text { in the }\end{array}$ \\
\hline $\begin{array}{l}\text { Can be processed mar } \\
\text { spreadsheets without } \\
\text { complex processing o }\end{array}$ & $\begin{array}{l}\text { on experienced facilitator(s) to manage } \\
\text { at use of expert interaction - more so with } \\
\text { nore complex problems. }\end{array}$ \\
\hline $\begin{array}{l}\text { Process is auditable and repeatable } \\
\text { thereby, offering advantages over less } \\
\text { formal methods. }\end{array}$ & $\begin{array}{l}\text { Interpretive ranking model is complex to develop and } \\
\text { difficult to interpret for larger problems and has more } \\
\text { limited value in these scenarios due to the number of } \\
\text { represented visual interdependencies between } \\
\text { factors. }\end{array}$ \\
\hline $\begin{array}{l}\text { Includes key validation points in the } \\
\text { dominance matrix via the summation of } \\
\text { the net dominance, cross validation } \\
\text { between matrices and structured } \\
\text { walkthrough to confirm interpretive } \\
\text { logic. }\end{array}$ & $\begin{array}{l}\text { Potential significant workload (dependent on } \\
\text { problem complexity) and subsequent reliance on } \\
\text { experts for number of steps in the model; greater than } \\
\text { other interpretive methods such as ISM. }\end{array}$ \\
\hline
\end{tabular}




\section{About the Authors}

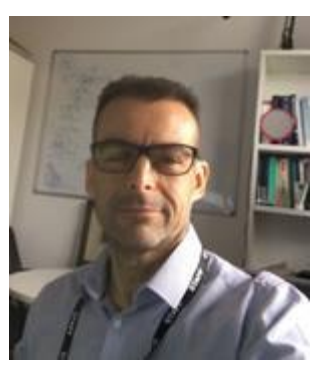

Laurie Hughes is a Lecturer in Strategic Operations within the Emerging Markets Research Centre at the School of Management Swansea University UK. He has a wide range of research interests in the area of Information Systems (IS), business processes and adoption of technology within government and wider emerging markets. He has published in a range of academic journals including: Annals of Operations Research, Applied Energy, Production and Planning Control, International Journal of Information Management and Journal of Enterprise Information Management. Laurie has extensive experience with industry working for large consultancies within government, manufacturing, Ministry of Defence and private sector organisations.

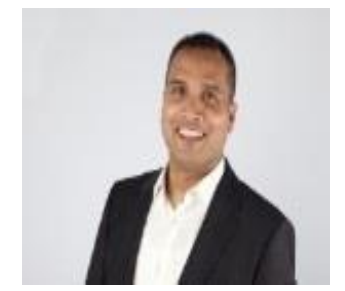

Yogesh K. Dwivedi is a Professor of Digital Marketing and Innovation, Founding Director of the Emerging Markets Research Centre $(\mathrm{EMaRC})$ and Co-Director of Research at the School of Management, Swansea University, Wales, UK. Professor Dwivedi is also currently leading the International Journal of Information Management as its Editor-in-Chief. His research interests are at the interface of Information Systems (IS) and Marketing, focusing on issues related to consumer adoption and diffusion of emerging digital innovations, digital government, and digital marketing particularly in the context of emerging markets. Professor Dwivedi has published more than 300 articles in a range of leading academic journals.

Nripendra P. Rana is a Professor in Digital Marketing and the Head of International Business, Marketing and Branding at the School of Management, University of Bradford, UK. His research includes: adoption and diffusion of emerging ICTs, ecommerce, m-commerce, e-government, digital and social media marketing. He has

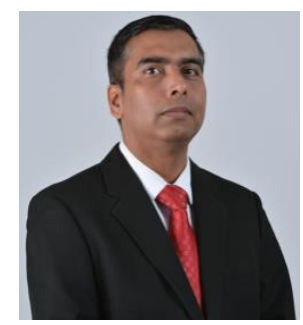
published more than 180 articles within leading academic journals and conferences. He has co-edited five books on digital and social media marketing, emerging markets and supply and operations management. $\mathrm{He}$ is an Associate Editor of International Journal of Information Management. He is also a Visiting Scholar of Indian Institute of Management Tiruchirappalli in India. 